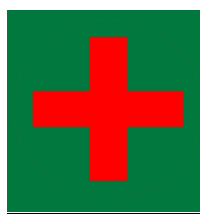

\title{
Tinjauan Kualitas Pelayanan Pasien JKN Non PBI di Instalasi Rawat Jalan Puskesmas Batua Kota Makassar
}

\author{
Leni Karunia Septiani ${ }^{1}$, Nanda Aula Rumana ${ }^{2}$, Deasy Rosmala Dewi ${ }^{3}$, Noor Yulia ${ }^{4}$ \\ ${ }^{1,2,3,4}$ Program Studi D-3 Rekam Medis dan Informasi Kesehatan, Fakultas Ilmu-Ilmu \\ Kesehatan, Universitas Esa Unggul, DKI Jakarta, Indonesia \\ Email: ${ }^{1}$ lenikarunia20180306046@gmail.com
}

\begin{abstract}
Service quality comes from the comparison of what consumers feel (expectations) with consumer perceptions about the performance of companies that provide services. The purpose of this study was to describe the quality of service for JKN non-PBI patients at the Batua Public Health Center in Makassar. The method used is quantitative analysis with descriptive method. Calculation of sample size using the proportion estimation formula obtained 96 samples with the sampling method, namely Incidental/Convenience Sampling. Data collection techniques using interviews and self-filling by patients with interview guide instruments and questionnaires, and data were analyzed using SPSS. Service quality is assessed based on 5 dimensions, namely Tangible, Responsiveness, Reliability Assurance and Empathy. From the results of the study, it was found that the percentage of service quality at Batua Health Center was $57.3 \%$ of good service quality and $42.7 \%$ not good, meaning that the service quality was classified as not good because $\leq 90 \%$ based on outpatient SPM. Obstacles that often occur when serving patients such as problems with communication tools/speakers, lack of computers, patients do not want to queue and do not bring medical cards/BPJS cards/identity cards. It is recommended to the Puskesmas to pay more attention to the cleanliness and comfort of the registration place, the officers should improve their competence, advance working hours so that there are no delays in opening the counter, apply $3 S$ 1T, pay attention to the problematic speakers and computers as well as socialize the files that must be brought during registration.
\end{abstract}

Keywords: Quality of service, JKN non PBI, Outpatient.

\begin{abstract}
Abstrak
Kualitas pelayanan berasal dari perbandingan apa yang konsumen rasakan (ekspektasi) dengan persepsi konsumen tentang kinerja perusahaan yang menyediakan jasa. Tujuan penelitian ini untuk mengetahui gambaran kualitas pelayanan pasien JKN non PBI di instalasi rawat jalan Puskesmas Batua kota Makassar. Metode yang digunakan adalah analisis kuantitatif dengan metode deskriptif. Perhitungan besar sampel menggunakan rumus estimasi proporsi didapatkan 96 sampel dengan metode pengambilan sampel yaitu Incidental/Convenience Sampling. Teknik pengumpulan data menggunakan wawancara dan pengisian sendiri oleh pasien dengan instrumen pedoman wawancara dan angket, dan data dianalisis menggunakan SPSS. Kualitas pelayanan dinilai berdasarkan 5 dimensi yaitu Tangible, Responsivenes, Reliability Assurance dan Empathy. Dari hasil penelitian didapatkan persentase kualitas pelayanan di Puskesmas
\end{abstract}


Batua sebesar 57,3\% kualitas pelayanan baik dan 42,7\% tidak baik, artinya kualitas pelayanannya tergolong tidak baik karena $\leq 90 \%$ berdasarkan SPM rawat jalan. Kendala yang sering terjadi saat melayani pasien seperti masalah alat komunikasi/speaker, kekurangan komputer, pasien tidak mau antri dan tidak membawa kartu berobat/kartu BPJS/identitas. Disarankan kepada Puskesmas untuk lebih memperhatikan kebersihan dan kenyamanan tempat pendaftaran, sebaiknya petugas meningkatkan kompetensinya, jam kerja dimajukan agar tidak ada keterlambatan membuka loket, menerapkan 3S 1T, memperhatikan speaker dan komputer yang bermasalah juga mensosialisasikan kepada pasien berkas yang harus dibawa saat pendaftaran.

Kata Kunci: Kualitas Pelayanan, Jaminan Kesehatan Nasional non PBI, Rawat Jalan.

\section{PENDAHULUAN}

Puskesmas adalah fasilitas pelayanan kesehatan yang menyelenggarakan upaya kesehatan masyarakat dan upaya kesehatan perseorangan tingkat pertama, dengan lebih mengutamakan upaya promotif dan preventif di wilayah kerjanya (Menkes RI, 2019).

Jaminan kesehatan adalah jaminan berupa perlindungan kesehatan agar peserta memperoleh manfaat pemeliharaan kesehatan dan perlindungan dalam memenuhi kebutuhan dasar kesehatan yang diberikan kepada setiap orang yang telah membayar iuran atau iurannya dibayar oleh pemerintah. Peserta jaminan kesehatan terdiri dari Penerima Bantuan Iuran (PBI) dan Bukan Penerima Bantuan Iuran (non PBI) (Presiden RI, 2013). Pasien non PBI adalah pasien yang membayar iurannya sendiri berarti memiliki penghasilan yang lebih tinggi, karena mempunyai penghasilan lebih tinggi maka tingkat pendidikannya juga tinggi di banding pasien PBI. Hasil penelitian Risya Amalina, Titik Respati, \& Budiman menyebutkan sebagian besar peserta PBI memiliki pengetahuan yang kurang sedangkan pasien non PBI memiliki pengetahuan yang baik. Tingkat pendidikan yang tinggi dapat meningkatkan pengetahuan masyarakat tentang pemanfaatan layanan kesehatan (Amalina et al., 2015).

Kualitas pelayanan berasal dari perbandingan tentang apa yang konsumen rasakan yaitu ekspektasi mereka dengan persepsi konsumen tentang kinerja perusahaan yang menyediakan jasa (Parasuraman et al., 1988). Pelayanan yang bermutu dapat dilihat dari kualitas pelayanannya. Jika kualitas pelayanan kesehatannya rendah maka pasien akan merasa tidak puas. Ketidakpuasan ini mempengaruhi jumlah kunjungan pasien (Azzahroh, 2017) dan pindahnya pasien ke fasilitas layanan kesehatan lain (Pohan, 2007).

Berdasarkan hasil penelitian yang dilakukan Desi Ratnasari, Misnaniarti, Yuanita Windusari tahun 2019 didapatkan bahwa responden yang merasa kurang puas terhadap kualitas pelayanan keseluruhan ada $79(52,3 \%)$ responden dan yang merasa puas 72 $(47,7 \%)$ responden (Ratnasari et al., 2020). Sedangkan menurut penelitian Rosi Damayanti, Nanda Aula Rumana tahun 2017 pasien BPJS yang merasa puas pada pelayanan unit rawat jalan $51,7 \%$ dan $48,3 \%$ pasien yang merasa tidak puas (Damayanti \& Rumana, 2017). Sehingga dari penelitan tersebut dapat disimpulkan bahwa pasien yang merasa tidak puas dengan kualitas pelayanan di rawat jalan masih banyak.

Dilihat dari pengukuran tingkat kepuasan pasien berdasarkan peraturan menteri kesehatan No/129/Menkes/SK/II/2008 tentang Standar Pelayanan Minimal Rumah 
Sakit bahwa salah satu standar minimal rawat jalan yaitu kepuasan pelanggan $>90 \%$ (lebih dari 90\%) terhadap pelayanan yang diberikan (Menkes RI, 2008). Berdasarkan penjelasan pada latar belakang masalah tersebut, maka dapat dirumuskan masalah dalam penelitian ini adalah bagaimana gambaran kualitas pelayanan pasien JKN non PBI di instalasi rawat jalan Puskesmas Batua Kota Makassar?. adapun tujuan penelitian ini adalah untuk mengetahui gambaran kualitas pelayanan pasien JKN non PBI di instalasi rawat jalan Puskesmas Batua kota Makassar.

\section{METODE}

Metode yang digunakan adalah metode deskriptif. Populasinya adalah seluruh pasien JKN non PBI yang berobat di instalasi rawat jalan Puskesmas Batua pada bulan April 2021. Sampel dalam penelitian ini adalah seluruh pasien JKN non PBI yang berobat di instalasi rawat jalan Puskesmas Batua pada bulan April 2021 yang terpilih pada saat penelitian dengan jumlah besar sampel menggunakan rumus estimasi proporsi didapatkan hasil 96 sampel. Cara pengambilan sampel menggunakan Incidental/Convenience Sampling (sampel seadanya). Teknik pengumpulan data menggunakan wawancara dengan instrumen pedoman wawancara dan teknik pengisian sendiri oleh responden dengan instrumen pengumpulan data menggunakan angket. Data yang didapatkan dianalisis menggunakan software statistik SPSS (Statistical Package for the Social Sciences).

\section{HASIL}

A. Standar Prosedur Operasional (SPO) pendaftaran rawat jalan di Puskesmas Batua kota Makassar.

Di Puskesmas Batua Kota Makassar sudah terdapat SPO pendaftaran rawat jalan. Diterbitkan pada tanggal 12 maret 2015, di sosialisasikan tanggal 15 maret 2015 dan mulai berlaku tanggal 1 april 2015- sekarang.

B. Gambaran kualitas pelayanan pasien JKN non PBI di instalasi rawat jalan melalui 5 dimensi kualitas pelayanan di Puskesmas Batua kota Makassar.

Tabel 1. Penilaian responden terhadap kualitas pelayanan pasien JKN non PBI di instalasi rawat jalan melalui 5 dimensi kualitas pelayanan di Puskesmas Batua

\begin{tabular}{|c|c|c|c|c|c|}
\hline \multirow{2}{*}{ NO } & \multirow{2}{*}{ PERNYATAAN } & \multicolumn{2}{|c|}{ Sesuai } & \multicolumn{2}{|c|}{ Tidak Sesuai } \\
\hline & & $\mathbf{N}$ & $\%$ & $\mathbf{N}$ & $\%$ \\
\hline \multicolumn{6}{|c|}{ Tangible (Bukti nyata) } \\
\hline 1. & $\begin{array}{l}\text { Kebersihan dan kenyamanan tempat } \\
\text { pendaftaran }\end{array}$ & 26 & 27,1 & 70 & 72,9 \\
\hline 2. & $\begin{array}{l}\text { Selalu ada kursi kosong untuk menunggu } \\
\text { ditempat pendaftaran }\end{array}$ & 38 & 39,6 & 58 & 60,4 \\
\hline 3. & $\begin{array}{c}\text { Kebersihan dan kerapihan Petugas } \\
\text { pendaftaran/rekam medis }\end{array}$ & 47 & 49 & 49 & 51 \\
\hline 4. & $\begin{array}{l}\text { Map rekam medis anda terawat dan tidak } \\
\text { kusut/robek }\end{array}$ & 43 & 44,8 & 53 & 55,2 \\
\hline 5. & Tersedia nomor urut & 79 & 82,3 & 17 & 17,7 \\
\hline
\end{tabular}




\begin{tabular}{|c|c|c|c|c|c|}
\hline \multicolumn{6}{|c|}{ Responsiveness (Daya tanggap) } \\
\hline 1. & Waktu tunggu diloket pendaftaran sebentar & 15 & 15,6 & 81 & 84,4 \\
\hline 2. & Petugas mengarahkan segera ke poliklinik & 36 & 37,5 & 60 & 62,5 \\
\hline 3. & $\begin{array}{l}\text { Petugas tahu apa yang dibutuhkan pasien } \\
\text { (merespon cepat masalah pasien) }\end{array}$ & 36 & 37,5 & 60 & 62,5 \\
\hline \multicolumn{6}{|c|}{ Reliability (Kehandalan) } \\
\hline 1. & $\begin{array}{l}\text { Kejelasan informasi jadwal buka/tutup loket } \\
\text { pendaftaran }\end{array}$ & 43 & 44,8 & 53 & 55,2 \\
\hline 2. & Ketepatan waktu buka loket pendaftaran & 37 & 38,5 & 59 & 61,5 \\
\hline 3. & $\begin{array}{l}\text { Petugas pendaftaran mengarahkan ke } \\
\text { poliklinik }\end{array}$ & 48 & 50 & 48 & 50 \\
\hline 4. & $\begin{array}{l}\text { Petugas pendaftaran mengetahui apa yang } \\
\text { dibutuhkan pasien }\end{array}$ & 48 & 50 & 48 & 50 \\
\hline 5. & $\begin{array}{l}\text { Kemudahan dalam pendaftaran/prosedur } \\
\text { administrasi }\end{array}$ & 65 & 67,7 & 31 & 32,3 \\
\hline 6. & $\begin{array}{c}\text { Pelayanan pasien disesuaikan dengan } \\
\text { urutannya, tidak ada pasien yang } \\
\text { menyerobot antrian }\end{array}$ & 73 & 76 & 23 & 24 \\
\hline \multicolumn{6}{|c|}{$\begin{aligned} \text { Assurance (Jaminan) } \\
\end{aligned}$} \\
\hline 1 & $\begin{array}{l}\text { Petugas pendaftaran/perekam medis terampil } \\
\text { ketika melayani anda }\end{array}$ & 62 & 64,6 & 34 & 35,4 \\
\hline 2 & $\begin{array}{l}\text { Petugas pendaftaran/perekam medis sopan } \\
\text { dan ramah ketika melayani anda }\end{array}$ & 70 & 72,9 & 26 & 27,1 \\
\hline \multicolumn{6}{|c|}{ Emphaty (Empati) } \\
\hline 1. & $\begin{array}{l}\text { Ketulusan petugas pendaftaran melayani } \\
\text { pasien }\end{array}$ & 71 & 74 & 25 & 26 \\
\hline 2. & Penjelasan petugas ketika anda bertanya & 71 & 74 & 25 & 26 \\
\hline 3. & Petugas selalu diloket & 72 & 75 & 24 & 25 \\
\hline 4. & $\begin{array}{l}\text { Ketika antrian panjang, petugas mengurangi } \\
\text { jam istirahatnya dan terus melayani pasien }\end{array}$ & 55 & 57,3 & 41 & 42,7 \\
\hline 5 . & $\begin{array}{l}\text { Petugas pendaftaran/perekam medis selalu } \\
\text { senyum pada pasien }\end{array}$ & 46 & 47,9 & 50 & 52,1 \\
\hline
\end{tabular}

Berdasarkan tabel 1 dapat dilihat pada dimensi Tangible (bukti nyata) pernyataan yang paling banyak pasien menyatakan tidak sesuai adalah kebersihan dan kenyamanan tempat pendaftaran sebanyak 70 (72,9\%). Dimensi Responsiveness (daya tanggap) pada pernyataan waktu tunggu diloket pendaftaran sebentar sebanyak $81(84,4 \%)$. Dimensi Reliability (kehandalan) pasien menyatakan tidak sesuai pada ketepatan waktu buka loket pendaftaran sebanyak 59 (61,5\%). Untuk dimensi Assurance (jaminan) pada pernyataan petugas pendaftaran/ perekam medis terampil ketika melayani pasien sebanyak 34 (35,4\%). Dan dimensi Emphaty (empati) pernyataan yang paling banyak pasien menyatakan tidak sesuai adalah petugas pendaftaran/perekam medis selalu senyum pada pasien sebanyak $50(52,1 \%)$.

Tabel 2. kualitas pelayanan pasien JKN non PBI di instalasi rawat jalan melalui 5 dimensi kualitas pelayanan di Puskesmas batua Kota Makassar.

\begin{tabular}{ccc}
$\begin{array}{c}\text { Dimensi Kualitas } \\
\text { Pelayanan }\end{array}$ & Jumlah & Persentase \\
& $(\mathrm{N})$ & $(\%)$ \\
\hline
\end{tabular}




\begin{tabular}{|c|c|c|}
\hline \multicolumn{3}{|c|}{ Tangible (Bukti nyata) } \\
\hline kualitas pelayanan baik & 54 & 56,3 \\
\hline kualitas pelayanan tidak baik & 42 & 43,8 \\
\hline Total & 96 & 100 \\
\hline \multicolumn{3}{|c|}{$\begin{array}{r}\text { Responsiveness (Daya tanggap) } \\
\end{array}$} \\
\hline kualitas pelayanan baik & 49 & 51 \\
\hline kualitas pelayanan tidak baik & 47 & 49 \\
\hline Total & 96 & 100 \\
\hline \multicolumn{3}{|c|}{ Reliability (Kehandalan) } \\
\hline kualitas pelayanan baik & 51 & 53,1 \\
\hline kualitas pelayanan tidak baik & 45 & 46,9 \\
\hline Total & 96 & 100 \\
\hline \multicolumn{3}{|c|}{$\begin{array}{r}\text { Assurance (Jaminan) } \\
\end{array}$} \\
\hline kualitas pelayanan baik & 61 & 63,5 \\
\hline kualitas pelayanan tidak baik & 35 & 36,5 \\
\hline Total & 96 & 100 \\
\hline \multicolumn{3}{|c|}{ Emphaty (Empati) } \\
\hline kualitas pelayanan baik & 59 & 61,5 \\
\hline kualitas pelayanan tidak baik & 37 & 38,5 \\
\hline Total & 96 & 100 \\
\hline
\end{tabular}

Berdasarkan tabel 2 menunjukkan bahwa 54 (56,3\%) pasien merasa kualitas pelayanan baik pada dimensi Tangible (bukti Nyata) dan $42(43,8 \%)$ merasa kualitas pelayanan tidak baik. Pada diemensi Responsiveness (Daya tanggap) 49 (51\%) pasien merasa kualitas pelayanan baik dan 47 (49\%) merasa kualitas pelayanan tidak baik. Untuk dimensi Reliability (Kehandalan) $51(53,1 \%)$ pasien merasa kualitas pelayanan baik dan $45(46,9 \%)$ merasa kualitas pelayanan tidak baik. Pada dimensi Assurance (Jaminan) $61(63,5 \%)$ pasien merasa kualitas pelayanan baik dan $35(36,5 \%)$ merasa kualitas pelayanan tidak baik. Dimensi Emphaty (Empati) 59 (61,5\%) pasien merasa kualitas pelayanan baik dan $37(38,5 \%)$ merasa kualitas pelayanan tidak baik.

Tabel 3. Rekapitulasi kualitas pelayanan pasien JKN non PBI di instalasi rawat jalan Puskesmas batua Kota Makassar

\begin{tabular}{ccc}
\hline Kualitas Pelayanan & $\begin{array}{c}\text { Jumlah } \\
(\mathbf{N})\end{array}$ & $\begin{array}{c}\text { Persentase } \\
(\boldsymbol{\%})\end{array}$ \\
\hline kualitas pelayanan baik & 55 & 57,3 \\
\hline $\begin{array}{c}\text { kualitas pelayanan tidak } \\
\text { baik }\end{array}$ & 41 & 42,7 \\
\hline Total & 96 & 100 \\
\hline
\end{tabular}

Tabel 3 menunjukkan persentase akhir kualitas pelayanan berdasarkan ke-5 dimensi. Persentase kualitas pelayanan pasien JKN non PBI di instalasi rawat jalan Puskesmas Batua sebesar 57,3\% kualitas pelayanan baik dan 42,7\% kualitas pelayanan tidak baik.

\section{Kendala Pelayanan pasien JKN non PBI pada instalasi rawat jalan di} Puskesmas Batua kota Makassar 
Berdasarkan dari hasil wawancara kepada 4 petugas pendaftaran di Instalasi rawat jalan didapatkan hasil sebagai berikut:

Pertanyaan "Apakah terdapat SPO pelayanan pendaftaran pasien rawat jalan?" didapatkan hasil bahwa sudah terdapat SPO pelayanan pendaftaran pasien rawat jalan. Pertanyaan kedua "Apakah ada perbedaan antara pelayanan pasien PBI dan non PBI?" didapatkan hasil bahwa tidak terdapat perbedaan antara pelayanan pasien PBI dan non PBI. Untuk pertanyaan ke tiga "Apakah terdapat prosedur dalam SPO pelayanan yang tidak dilakukan?" didapatkan hasil bahwa tidak ada prosedur dalam SPO pelayanan yang tidak dilakukan. Pertanyaan ke empat "Apakah ada kesulitan dalam melaksanakan apa yang sudah ditetapkan dalam SPO ?" didapatkan hasil bahwa petugas tidak mengalami kesulitan dalam melaksanakan apa yang sudah ditetapkan dalam SPO. Pada pertanyaan ke lima "Berapakah jumlah petugas pendaftaran pasien rawat jalan di Puskesmas Batua?" didapatkan hasil bahwa jumlah petugas pendaftaran pasien rawat jalan di Puskesmas Batua ada 4 petugas pendaftaran. Pertanyaan ke enam "Apakah jumlah SDM/petugas di pendaftaran pasien rawat jalan cukup?" didapatkan hasil bahwa jumlah SDM/petugas di pendaftaran pasien rawat jalan sudah cukup. Pertanyaan ke tujuh "Apakah anda kelelahan dalam menangani banyaknya pasien yang berkunjung untuk berobat ?" didapatkan hasil bahwa petugas tidak kelelahan dalam menangani banyaknya pasien yang berkunjung untuk berobat. Pertanyaan ke delapan "Apakah ada kendala/masalah yang sering terjadi saat melayani pasien?" didapatkan hasil bahwa ada kendala/masalah yang sering terjadi saat melayani pasien seperti masalah alat komunikasi/speaker, kekurangan komputer, pasien yang tidak mau antri dan tidak membawa kartu berobat/kartu BPJS/identitas. Untuk pertanyaan ke Sembilan "Apakah di puskesmas ini ada petugas BPJS/JKN?" didapatkan hasil bahwa tidak ada petugas khusus untuk BPJS/JKN. Dan untuk pertanyaan terakhir "Berapakah kunjungan ratarata keseluruhan pasien rawat jalan peserta BPJS perhari?" didapatkan hasil bahwa kunjungan rata-rata pasien BPJS rawat jalan perhari sekitar 70-80 orang sebelum pandemik dan 30-40 orang selama pandemik.

\section{PEMBAHASAN}

\section{A. Standar Prosedur Operasional (SPO) pelayanan pendaftaran rawat jalan di Puskesmas Batua kota Makassar.}

Berdasarkan hasil wawancara dengan petugas pendaftaran rawat jalan didapatkan bahwa sudah terdapat Standar Prosedur Operasional (SPO) pada pelayanan pendaftaran rawat jalan di Puskesmas Batua Kota Makassar yang diterbitkan tanggal 12 maret 2015 ,di sosialisasikan tanggal 15 maret 2015 dan mulai berlaku tanggal 1 april 2015sekarang. SPO ini menjadi acuan bagi petugas dalam melakukan pelayanan pendaftaran rawat jalan. SPO adalah serangkaian instruksi baku yang mengatur instruksi/langkahlangkah untuk menyelesaikan proses kerja rutin (KARS, 2012).

B. Gambaran kualitas pelayanan pasien JKN non PBI di instalasi rawat jalan melalui 5 dimensi kualitas pelayanan yaitu Tangible (Bukti nyata), Responsiveness (Daya tangkap), Reliability (Kehandalan), Assurance (Jaminan), dan Emphaty (Empati) di Puskesmas Batua kota Makassar.

Dimensi Tangible (Bukti nyata) meliputi penyediaan fasilitas yang digunakan dan penampilan petugas (Parasuraman et al., 1988). Dari penjabaran hasil penelitian 
didapatkan dimensi Tangible (Bukti nyata) tergolong dimensi terendah ke tiga. Persentase kualitas pelayanan $54(56,3 \%)$ pasien merasa kualitas pelayanan baik dan 42 $(43,8 \%)$ merasa kualitas pelayanan tidak baik. Hasil penelitian ini sejalan dengan penelitian yang dilakukan oleh Sri Yuniarti, Parjo, dan Abror Irsan tahun 2015 bahwa $43(43,0 \%)$ pasien menyatakan kualitas baik dan $12(12,0 \%)$ pasien menyatakan kualitas kurang baik (Yuniarti et al., 2015)

Dimensi Responsiveness (Daya tanggap) meliputi kesediaan petugas membantu pelanggan dan memberikan pelayanan dengan tanggap/sigap (Parasuraman et al., 1988). Dari penjabaran hasil penelitian didapatkan dimensi Responsiveness (Daya tanggap) tergolong dimensi paling rendah. Persentase kualitas pelayanan $49(51 \%)$ pasien merasa kualitas pelayanan baik dan 47 (49\%) merasa kualitas pelayanan tidak baik. Hasil penelitian ini sejalan dengan penelitian Wulan Puspitasari, Neno Fitriyani tahun 2016 bahwa $232(64,4 \%)$ pasien merasa mutu pelayanan baik dan $128(35,6 \%)$ pasien merasa mutu pelayanan kurang baik (Puspitasari \& Fitriyani, 2016).

Dimensi Reliability (Kehandalan) meliputi kehendak, kemampuan memberikan pelayanan dengan segera, andal, akurat dan memuaskan (Parasuraman et al., 1988). Dari penjabaran hasil penelitian didapatkan dimensi Reliability (Kehandalan) adalah dimensi terendah kedua. Persentase kualitas pelayanan $51(53,1 \%)$ pasien merasa kualitas pelayanan baik dan 45 (46,9\%) merasa kualitas pelayanan tidak baik. Hal ini sejalan dengan penelitian Afdi Subianto, La Ode Ali Imran Ahmad, Lade Albar Kalza tahun 2019 bahwa $89(52,7 \%)$ pasien merasa mutu pelayanan baik dan $80(47,3 \%)$ pasien merasa mutu pelayanan kesehatan kurang (Subianto et al., 2019)

Dimensi Assurance (Jaminan) mencakup pengetahuan, kemampuan, kesopanan karyawan dan sifat yang dapat dipercaya (Parasuraman et al., 1988). Dari penjabaran hasil penelitian didapatkan dimensi Assurance (Jaminan) adalah dimensi terbaik. Persentase kualitas pelayanan $61(63,5 \%)$ pasien merasa kualitas pelayanan baik dan 35 $(36,5 \%)$ merasa kualitas pelayanan tidak baik. Hal ini sejalan dengan penelitian Wulan Puspitasari, Neno Fitriyani tahun 2016 bahwa 240 (66,7\%) pasien merasa mutu pelayanan baik dan 120 (33,3\%) merasa kurang baik (Puspitasari \& Fitriyani, 2016).

Dimensi Empathy (Empati) mencakup peduli, kemudahan didalam melakukan komunikasi, hubungan antar personal yang baik, perhatian dan memahami kebutuhan pelanggan (Parasuraman et al., 1988). Dari penjabaran hasil penelitian didapatkan dimensi Emphaty (Empati) adalah dimensi tertinggi kedua. Persentase kualitas pelayanan 59 (61,5\%) pasien merasa kualitas pelayanan baik dan 37 (38,5\%) merasa kualitas pelayanan tidak baik. Hal ini sejalan dengan hasil penelitian Aida andriani tahun 2017 bahwa $38(58,5 \%)$ pasien merasa mutu pelayanan baik dan $27(41,5 \%)$ pasien merasa mutu pelayanan kurang baik (Andriani, 2017).

Berdasarkan penelitian terhadap kualitas pelayanan pasien JKN non PBI di instalasi rawat jalan Puskesmas Batua Kota Makassar dengan menggunakan Servqual/ service Quality mencakup 5 dimensi yaitu Tangible, Responsiveness, Reliability, Assurance, dan Emphaty. Secara keseluruhan didapatkan hasil 55 (57,3\%) pasien menilai kualitas pelayanan baik dan $41(42,7 \%)$ pasien menilai kualitas pelayanan tidak baik. Kualitas pelayanan di Puskesmas Batua tergolong tidak baik karena persentasi kualitas pelayanan baik hanya 57,3\%, sedangkan menurut Standar pelayanan Minimal rawat jalan kualitas pelayanan baik jika skor $\geq 90 \%$ (Menkes RI, 2008). 
Puskesmas harus selalu meningkatkan kualitas pelayanannya agar dapat meningkatkan derajat kesehatan masyarakat. Kualitas pelayanan kesehatan yaitu tingkat kesempurnaan pelayanan kesehatan yang dapat menimbulkan rasa puas pada diri pasien. Makin sempurna kepuasan tersebut, makin baik pula kualitas pelayanan kesehatan (Mamik, 2017). Kualitas pelayanan yang baik memberikan dampak positif bagi kesembuhan pasien (Khoiri \& Hermastutik, 2014).

\section{Kendala pelayanan pasien JKN non PBI pada instalasi rawat jalan di Puskesmas Batua kota Makassar.}

Dari penjabaran hasil wawancara kepada 4 petugas pendaftaran didapatkan hasil bahwa sudah terdapat SPO pelayanan pendaftaran pasien rawat jalan. Tujuan dibuatnya SPO agar berbagai proses kerja rutin terlaksana dengan efektif, efisien, seragam/ konsisten dan aman, dalam rangka meningkatkan kualitas pelayanan melalui pemenuhan standar yang berlaku (KARS, 2012). Dari hasil wawancara kepada petugas pendaftaran didapatkan bahwa ada kendala/masalah yang sering terjadi saat melayani pasien seperti masalah alat komunikasi/speaker, kekurangan komputer, pasien yang tidak mau antri dan tidak membawa kartu berobat/kartu BPJS/identitas, juga kendala lainnya berdasarkan observasi penulis yaitu jaringan yang kurang baik. Dengan kendala ini menyebabkan pelayanan terhambat.

\section{KESIMPULAN DAN SARAN}

Berdasarkan hasil penelitian diatas, dapat disimpulkan sebagai berikut:

Pada pelayanan pendaftaran rawat jalan Puskesmas Batua Kota Makassar sudah terdapat Standar Prosedur Operasional (SPO). Gambaran kualitas pelayanan pasien JKN non PBI di instalasi rawat jalan Puskesmas Batua kota Makassar melalui dimensi Tangible (Bukti nyata) didapatkan $54(56,3 \%)$ pasien merasa kualitas pelayanan baik dan 42 (43,8\%) merasa tidak baik. Dimensi Responsiveness (Daya tangkap) 49 (51\%) pasien merasa kualitas pelayanan baik dan 47 (49\%) merasa tidak baik. Dimensi Reliability (Kehandalan) $51(53,1 \%)$ pasien merasa kualitas pelayanan baik dan 45 $(46,9 \%)$ merasa tidak baik. Dimensi Assurance (Jaminan) 61 (63,5\%) pasien merasa kualitas pelayanan baik dan 35 (36,5\%) merasa tidak baik. Dimensi Empathy (Empati) $59(61,5 \%)$ pasien merasa kualitas pelayanan baik dan $37(38,5 \%)$ merasa tidak baik. Rekapitulasi kualitas pelayanan berdasarkan ke-5 dimensi didapatkan persentase kualitas pelayanan sebesar 57,3\% kualitas pelayanan baik dan $42,7 \%$ kualitas pelayanan tidak baik. Berdasarkan standar pelayanan minimal rawat jalan kualitas pelayanan dikatakan baik jika skor $\geq 90 \%$, jadi kualitas pelayanan di Puskes Batua masih di bawah standar. Kendala pelayanan pasien JKN non PBI di instalasi rawat jalan Puskesmas Batua Kota Massar adalah masalah alat komunikasi/speaker, kekurangan komputer, pasien yang tidak mau antri dan tidak membawa kartu berobat/kartu BPJS/identitas.

Saran dari peneliti untuk Puskesmas Batua dan petugas pendaftaran di instalasi rawat jalan. Puskesmas di harapkan lebih memperhatikan kebersihan dan kenyamanan tempat pendaftaran agar pasien nyaman berobat. Sebaiknya petugas datang lebih pagi sebelum waktunya loket di buka agar pasien tidak terlalu lama menunggu diloket pendaftaran. Sebaiknya petugas pendaftaran meningkatkan kompetensinya dengan mengikuti pelatihan atau seminar agar lebih terampil dalam melayani pasien. Petugas pendaftaran menerapkan 3S1T (senyum, salam, sapa, terimakasih) saat melayani pasien. Puskesmas sebaiknya memperhatikan speaker dan komputer yang bermasalah juga 
jaringan yang kurang baik agar pelayanan tidak terhambat. Petugas diharapkan mensosialisasikan kembali berkas-berkas yang perlu dibawa saat pendaftaran dan berobat agar pasien tidak lupa dan mengetahui berkas yang harus di bawa seperti kartu berobat/kartu BPJS/identitas dan lain-lain.

\section{DAFTAR PUSTAKA}

Amalina, R., Respati, T., \& Budiman. (2015). Tingkat Pengetahuan Jaminan Kesehatan Nasional Peserta Badan Penyelenggara Jaminan Sosial Kesehatan di Puskesmas Plered Kabupaten Purwakarta Tahun 2015. Prosiding Pendidikan Dokter. Universitas Islam Bandung. Bandung, 2-6. http://karyailmiah.unisba.ac.id/index.php/dokter/article/viewFile/2123/pdf

Andriani, A. (2017). Hubungan Mutu Pelayanan Kesehatan Dengan Kepuasan Pasien Diruangan Poli Umum Puskesmas Bukittinggi. Jurnal Endurance, 2(1), 45. https://doi.org/10.22216/jen.v2i1.461

Az-zahroh, T. N. (2017). Pengaruh Mutu Pelayanan Kesehatan Terhadap Tingkat Kepuasan Pasien Rawat Inap Di Ruang Dewasa Umum Rumah Sakit X Kabupaten Gresik. Psikosains, 12(2), 99-111. http://journal.umg.ac.id

Damayanti, R., \& Rumana, N. A. (2017). Tinjauan Kepuasan Pasien BPJS Terhadap Pelayanan Bagian Pendaftaran Rawat Jalan di Rumah Sakit Patria IKKT Tahun 2017. Volume Jurnal.

KARS. (2012). Panduan Penyusunan Dokumen Akreditasi. In Www.IndonesianPublichealth.Com. http://www.indonesian-publichealth.com/panduanpenyusunan-dokumen-akreditsi-puskesmas/

Khoiri, A. N., \& Hermastutik, K. (2014). Hubungan Mutu Pelayanan Keperawatan Dengan Kepuasan Pasien Pengguna Kartu BPJS Kesehatan di Puskesmas Mojowarno Kabupaten Jombang ( The Correlation The Quality Of Nursing Service And The Satisfaction Of The Patients Holding Bpjs Card In Health Service Cen. Jurnal Metabolisme, 3(2), 112-123.

Mamik. (2017). Manajemen Mutu Pelayanan Kesehatan Dan Kebidanan (M. K. Hj. Siti aisyah, S.Pd (ed.); cetakan pe). Penerbit Zifatama Jawara. https://books.google.co.id/books?id=C37ADwAAQBAJ\&pg=PA155\&dq=Strateg $\mathrm{i}+$ Terkini+Peningkatan+Mutu+Pelayanan+Kesehatan.\&hl=id\&sa=X\&ved=2ahU KEwjY1r75r9nsAhXk8XMBHQhkBHUQ6AEwAHoECAUQAg\#v=onepage\&q= Strategi Terkini Peningkatan Mutu Pelayanan Kesehatan.\&f=false

Menkes RI. (2008). Menteri Kesehatan Republik Indonesia No 129 tahun 2008 Tentang Standar Pelayanan Minimal RS (Vol. 49, pp. 1-55).

Menkes RI. (2019). Menkes nomor 43 tahun 2019 tentang puskesmas (Issue 2, pp. 1168).

Parasuraman, A., Zeithaml, V. ., \& Berry, L. . (1988). SERVQUAL: A Multiple-Item Scale for Measuring Consumer Perceptions of Service Quality. Wiley Encyclopedia of Management, https://doi.org/10.1002/9781118785317.weom090654

Pohan, I. S. (2007). Jaminan mutu layanan kesehatan: dasar-dasar pengertian dan penerapan (P. Widyastuti (ed.); cetakan I:). Penerbit Buku Kedokteran EGC. https://books.google.co.id/books?id=bO00Wy--

gOUC\&pg=PA144\&dq=kepuasan+pasien\&hl=id\&sa=X\&ved=2ahUKEwjP09Cl2 _sAhVDfH0KHQ6CCc8Q6AEwAnoECAUQAg\#v=onepage \&q=kepuasan pasien \& $\mathrm{f}=\mathrm{false}$

Presiden RI. (2013). Perpres RI nomor 12 Tahun 2013 tentang Jaminan Kesehatan (pp. $1-39)$. 
Puspitasari, W., \& Fitriyani, N. (2016). Pengaruh Mutu Pelayanan Terhadap Tingkat Kepuasan Pasien BPJS Rawat Jalan di Rumah Sakit Pertamina Bintang Amin Bandar Lampung Tahun 2016. Jurnal Ilmu Kedokteran Dan Kesehatan, 4(April), $1-13$.

Ratnasari, D., Misnaniarti, \& Windusari, Y. (2020). Analisis Kualitas Layanan Pasien Jaminan Kesehatan Nasional (JKN) Mandiri di Instalasi Rawat Jalan Rumah Sakit Umum Daerah (RSUD) Sekayu Tahun 2019. Jurnal Kesehatan Vokasional, 5(2), 74. https://doi.org/10.22146/jkesvo.48366

Subianto, A., Ahmad, L. O. A. I., \& Kalza, L. A. (2019). Hubungan Kualitas Pelayanan Kesehatan Terhadap Kepuasan Pasien Peserta Jaminan Kesehatan Nasional Non Penerima Bantuan Iuran (JKN-Non PBI) Pada Poli Rawat Jalan Rumah Sakit Aliyah 1 Kota Kendari Tahun 2019. 1(1), 1-9.

Yuniarti, S., Parjo, \& Irsan, A. (2015). Hubungan Antara Kualitas Pelayanan Rumah Sakit Dengan Tingkat Kepuasan Pasien BPJS di Ruang Perawatan RSUD Sultan Syarif Mohamad Alkadrie Kota Pontianak Tahun 2015. Jurnal Kesehatan Prima, $1-11$. 